to interment in the graveyard of dead paradigms. Like Berthelot. his lifelong scientific opponent. Duhem also contributed to the development of the modern theory of explosives. Perhaps because he was kept in Bordeaux for most of his academic life. Duhem did not have a stable of students who worked on his ideas, and this contributed to his scientific oblivion in France.

In his brilliant study The Origins of Modern Science, written nearly 30 years ago, Herbert Butterfield paid proper homage to the work of Duhem in laying bare the structure of mediaeval physical thought. From the viewpoint of the anticlerical republican establishment, Duhem's discovery of the genius of mediaeval Catholicism was as unwelcome as his embarrassingly cogent attacks on Berthelot's rotten thermochemistry. At least this was of more ideological significance than Duhemian fulminations on the shaky status of Maxwell's worm-eaten equations. As a right-wing, publicly conspicuous Catholic in the state university, Duhem had no chance of getting a chair in Paris. This probably made little difference to the fortunes of science. At the end of the nineteenth century, a new galaxy of scientists appeared in Paris and the provinces - the Curies, Perrin, Sabatier, Brillouin, Langevin - who were also acceptable ideologically to the Third Republic, an intolerant mistress intent on re-establishing France as a great scientific power. By a perverse logic of events, Duhem was also one of the main contributors to another of the Republic's successful programmes, the creation of a set of decent provincial faculties of science.

Stanley Jaki's book is the first complete study of Duhem. This extensive treatment of the life and work of the author of the most famous book on theory in physics, The Aim and Structure of Physical Theory (1906), can only be welcomed with serious reservations. Its defects issue from Jaki's uncompromising hostility towards the Third Republic and most of Duhem's enemies. In addition to the distortions resulting from Jaki's gut Catholicism, there are basic misconceptions concerning the French educational system (including grandes écoles in the Université) and the history of science in France (that Darwinism was pushed in the faculties of science). Often the style seems to be modelled on the first sentence of Areopagitica. Still, this is a book on an "uneasy genius" that deserves to be chewed and digested. In the end, historical truth remains as elusive as scientific truth, which, as Houllevigue said, "resembles more a woman in a veil than the resplendent nude that painters make arise out of a well".

H.W. Paul is Professor of History at the University of Florida, Gainesville, Florida 32611 , USA. His Knowledge to Power: The Rise of the Science Empire in France, 1860-1939, will be published by Cambridge University Press later this year.

\section{Beauty of defects}

\section{A.K. Jonscher}

Defects and Defect Processes in Nonmetallic Solids. By W. Hayes and A.M. Stoneham. Wiley:1985. Pp.472. £54.30,\$47.

EARLY concepts of solid state physics were developed on the model of a perfect crystal - an ideal which proved extremely fruitful in generating a whole new branch of science. While it was recognized from the outset that defects were an inevitable and often a highly beneficial ingredient in any real solid, for a long time it was considered sufficient to regard them as small perturbations of the perfect host lattice and, in any case, to treat them as isolated and non-interacting entities. Only gradually did the impact of developing technology - of, for example, heavily doped and later amorphous semiconductors, or the progressive refinement of semiconductor devices or superionic conductors - demand a better understanding of the fundamental processes involving defects. The interaction of defects, exemplified by the phrase "ecology of solid state pollution", as a keyword-conscious researcher described simultaneous diffusion of two impurities in silicon, became increasingly a topic of detailed study.

Hayes and Stoneham's book is an important and probably a unique addition to the literature of this subject. It is remarkable in several respects. First, it combines outstanding readability with a depth of treatment which can be deceptive in that it can give the reader the impression that he has understood a certain point, until on closer examination he will find that on any single page there may be several other matters raised which require further study. The treatment is made both interesting and illuminating by the frequent inclusion of summary tables and other "integrating" features which bring together aspects of the subject not normally found under one heading, such as a full-page glossary of the main species of excitons.

The second unusual feature is the inclusion of many theoretical discussions which start with the simplest concepts and bring in, sometimes almost as asides, progressive refinements of approach which demand much wider reading. If one wishes to delve further, the up-to-date bibliography is very helpful; if not, one has at least been left under no illusion that the simple picture is the end of the matter.

The following chapter headings give an impression of the sheer breadth of the book's contents: "Electronic Properties" (mainly of perfect lattices but with electron-hole drops thrown in for good measure); "Interatomic Forces and Atomic Motions" (including defects and amorphous solids); "Lattice Defects" (with a discussion of fast ionic conductors); "Spectroscopy of Solids" (with descriptions of optical, EPR and DLTS techniques); "Electronic Properties of Point Defects" (with a comprehensive review of defects in many different materials); "Radiation-induced Defect Processes" (ranging from radiation damage and ion implantation to laser annealing and photolysis); "Properties of Surfaces" (with special emphasis on defect phenomena and including a discussion of sintering); and finally "Special Systems" (which manages to include amorphous solids, metal-insulator transitions, intercalates and polymers).

The book will be a challenge to able final-year students - it will broaden their horizons but they should beware of becoming too engrossed in the detail while for post-graduates this will be an ideal text to provide the background to many research topics. Teachers, too, will here find inspiration, though it may be necessary to dig deep into the subsidiary literature to follow up the items which are mentioned almost casually in the text. To a large degree, this is much more than a didactic text and has many features of a reference source. The seemingly effortless way in which the authors treat a wealth of topics should not deceive anyone into thinking that things are all that easy.

A.K. Jonscher is Professor of Solid State Electronics in the Department of Physics, King's College London (KQC), Pulton Place, London SW6 SPR, UK

\section{NEW TITLES \\ THE ACID RAIN DEBATE \\ SCIENTIFIC, ECONOMIC, AND POLITICAL DIMENSIONS \\ Edked by Ernest J. Yanarella and Randal H. Ihara}

This collection of essays by noted academics, lawyers, energy administrators, and research analysts focuses on the political and legal aspects of the acid rain debate, the policy options for resolving the controversy, and the international dimensions of acid rain control. The book complements the impressive body of research from the natural sciences and is supplemented by a comprehensive annotated bibliography on acid rain and relevant social science research.
siography on acid rain and

Westrlew Press, September 1985. c.200 pages,ISBNO81337065 5,pb, E18.00 ACID RAIN AND TRANSPORTED AIR POLLUTANTS IMPUCATIONS FOR PUBLC POUCY

Orflce of Technology Acsesument Congress of the Untited States

Examining the subject from environmental health, social, economic, and geographic viewpoints, this timely book gives a balanced coverage of all aspects of the acid rain controversy

Unlpub, 1985, 330 pages

ISEN $0890590443, \mathrm{hb}, 22.00$

Stocked and distributed exclusively by

Bowker Publishing Co. Eraxmus House, 58-62 High strece. Epping, Essex CMI6 HEU
Tel: Eppling 77333 (STO 0378) 